Chapman University

Chapman University Digital Commons

Economics Faculty Articles and Research

Economics

1972

\title{
On Models of Commercial Fishing: The Traditional Literature Needs No Defenders
}

Vernon L. Smith

Chapman University, vsmith@chapman.edu

Follow this and additional works at: http://digitalcommons.chapman.edu/economics_articles

Part of the Aquaculture and Fisheries Commons, and the Economics Commons

\section{Recommended Citation}

Smith, Vernon L. "On Models of Commercial Fishing: The Traditional Literature Needs No Defenders." Journal of Political Economy, 80.4 (1972): 776-778.

This Article is brought to you for free and open access by the Economics at Chapman University Digital Commons. It has been accepted for inclusion in Economics Faculty Articles and Research by an authorized administrator of Chapman University Digital Commons. For more information, please contactlaughtin@chapman.edu. 


\section{On Models of Commercial Fishing: The Traditional Literature Needs No Defenders}

\section{Comments}

This article was originally published in Journal of Political Economy, volume 80, issue 4, in 1972.

\section{Copyright}

University of Chicago 


\section{On Models of Commercial Fishing: The Traditional Literature Needs No Defenders}

Vernon L. Smith

University of Massachusetts

The first alleged "flaw" in my model is that $K$ is treated as a unique measure of the number of firms or fishing vessels. Since I have already answered this point (Smith 1971) in another exchange with Fullenbaum, Carlson, and Bell (FCB) it will not be repeated here. Let me just say that $K$ is a measure of crowding externality in the cost function and is not an "index of inputs," as claimed by FCB. In my model the "degree of fishing pressure may change without changing $K$ " for the same reason as in any industry, namely, by each firm simply changing its output by varying its current inputs.

It is also claimed by FCB that my model uses the wrong cost function because industry cost "should" change in direct proportion to an increase in the number of vessels. Here FCB are simply making an assumption (which they are intitled to) and not asserting a law of nature. The assumption is consistent with my model since the FCB equations (9)-(10) are a special case of the cost function (2), as noted in Smith (1971). The assumption is very limiting, for it means that total industry cost depends only on $K$, with no possibility of different intensities of capital utilization and therefore different outputs and costs associated with different fish populations.

FCB are wrong in believing that when $d K / d X=-\left(F_{X} / F_{K}\right)>0$ this implies a "dynamic inconsistency." The conditions for $d K / d X>0$ are derived in Smith $(1968,1971)$. Equilibrium is defined by two conditions, $\dot{X}=F(X, K)=0$, and $\dot{K}=I(X, K)=0$. Stability in the neighborhood of a point $\left(X^{0}, K^{0}\right)$ is given by Olech's (1963) generalization of the RouthHurwicz conditions:

$$
\begin{gathered}
F_{X}+I_{K}<0, \\
F_{X} I_{K}-F_{K} I_{X}>0, \\
\text { either } F_{X} I_{K} \neq 0 \text {, or } F_{K} I_{X} \neq 0 .
\end{gathered}
$$

These conditions are consistent with $(d K / d X)=-\left(F_{X} / F_{K}\right)>0$ provided that, in equation $(2),-\left(F_{X} / F_{K}\right)<-\left(I_{X} / I_{K}\right), F_{K} \neq 0, I_{K} \neq 0$. 
This means that the curve $F(X, K)=0$ must have a smaller slope than $I(X, K)=0$ at an intersection. Thus, a point such as $R$ in figure 4 in Smith (1969) can be dynamically stable as shown, and FCB are mistaken on a purely technical point to argue that a positive $d K / d X$ is inconsistent with stability. (Also, the question of stability has nothing to do with whether $K$ or $X$ is regarded as the independent variable as suggested by FCB.)

But FCB are correct in noting that the special example, $x=\bar{x}$, used to illustrate my model, was dynamically unstable at point $C$ in figure 8 (Smith $1969)$. But the instability in this particular example, where the $I(X, K)$ function is independent of $K$ (so that $I_{K}=0$ and condition [1] violated), should not be misconstrued to mean that one always has instability when $F(X, K)=0$ has a positive slope.

Let me emphasize that it is a correct statement to say that the competitive equilibrium may require a larger or smaller amount of capital than sole ownership. The amount of capital will be smaller if the stable competitive equilibrium (unappropriated) is at $R$ in figure 1, while the "sole owner" that is, appropriated) equilibrium is at a point such as $S$ corresponding to a larger capital stock and larger fish population. But of course such a case can only occur when there is a region in which $d K / d X=-\left(F_{X} / F_{K}\right)>0$, as indicated in Smith (1969).

Clive Southey's paper correctly illustrates these possibilities in terms of the industry revenue and cost functions. As Southey notes, the question of stability cannot be analyzed directly in terms of the revenue and cost functions. Stability analysis requires one to examine the derivatives of the

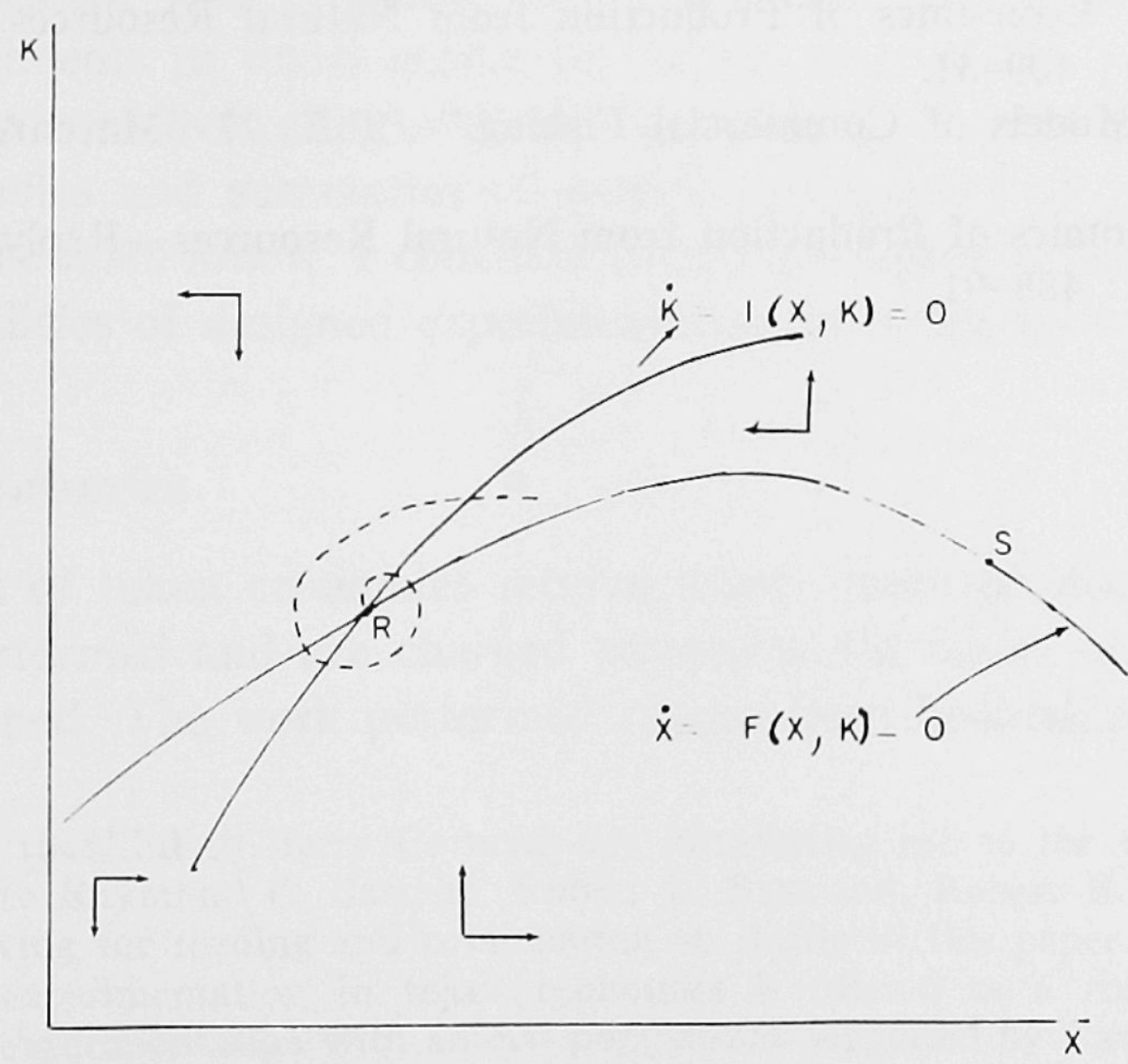

FIG. 1 
$F$ and $I$ functions by means of conditions (1)-(3), and not by comparing industry revenue and cost as attempted by FCB.

Once again FCB (n. 6) take the uninformed position that when $f_{1}>0$ my model implies that a subsidy $U=-\lambda f_{3}=K C_{2} f_{3} / f_{1}$ must be levied to produce Pareto optimality. Nothing could be further from the truth (Smith 1971). My paper (Smith 1969, p. 191) shows that Pareto optimality can only occur at a point where $f_{1}<0$, and that to hold an unappropriated free-access fishing at such an optimum requires a tax $U=-\lambda f_{3}$ (Smith 1969 , p. 195). That there may exist nonoptimal competitive unappropriated equilibria where $f_{1}>0$ has nothing to do with the question of optimal equilibrium taxes. Starting initially at some $X_{0}$ where $f_{1}>0$, a central control authority would have to levy a charge that reflects the implicit value (shadow price) of the fish stock at that point (see Quirk and Smith 1970, pp. 10-12). This would reduce the harvest, causing the fish stock to rise. The optimal dynamic charge would continuously change as the state of the system was guided toward the "golden rule" stationary equilibrium at some point, say $X^{0}$, where $f_{1}<0$, and a steady-state optimal tax would be levied. The failure cf FCB to understand the theory of such a social charge system does not inspire confidence.

\section{References}

Olech, C. "On the Global Stability of an Autonomous System on the Plane." Contributions to Differential Equations 1 (1963): 389-400.

Quirk, J. P., and Smith, V. L. "Dynamic Economic Models of Fishing." In Economics of Fisheries Management: A Symposium, edited by A. D. Scott. Vancouver: Inst. Animal Ecology, Univ. British Columbia, 1970.

Smith, V. L., "Economics of Production from Natural Resources." A.E.R. 58 (June 1968): 409-31.

- "On Models of Commercial Fishing." J.P.E. 77 (March/April 1969): 181-98.

"Economics of Production from Natural Resources-Reply." A.E.R. 61 (June 1971) : 488-91. 
Copyright of Journal of Political Economy is the property of University of Chicago Press and its content may not be copied or emailed to multiple sites or posted to a listserv without the copyright holder's express written permission. However, users may print, download, or email articles for individual use. 